\title{
Fermentation Patterns of Various Pectin Sources by Human Fecal Microbiota
}

\author{
Byungjick Min1, Ok Kyung Koo², Si Hong Park², Nathan Jarvis', Steven C. Ricke², \\ Philip G. Crandall ${ }^{1}$, Sun-Ok Lee ${ }^{*}$ \\ ${ }^{1}$ Department of Food Science, University of Arkansas, Fayetteville, USA \\ ${ }^{2}$ Center for Food Safety, University of Arkansas, Fayetteville, USA \\ Email: sunok@uark.edu
}

Received 26 August 2015; accepted 6 September 2015; published 9 September 2015

Copyright (C) 2015 by authors and Scientific Research Publishing Inc.

This work is licensed under the Creative Commons Attribution-NonCommercial International License (CC-

BY-NC).

http://creativecommons.org/licenses/by-nc/4.0/

c) (i) (9) Open Access

\begin{abstract}
High Methoxy Pectin (HMP), Sugar Beet Pectin (SBP), Soy Pectin (SOY), and Fructooligosaccharide (FOS, as a positive control) were used to determine fermentation properties considering applicability as functional foods, particularly related to colon health. Certain beneficial effects of carbohydrates in humans can be postulated as being due to microorganisms and metabolites (short-chain fatty acids (SCFAs)). Fecal samples were collected and incubated anaerobically with HMP, SBP, SOY, and FOS at $37^{\circ} \mathrm{C}$. The average degree of polymerization (DP) of HMP, SBP, and SOY was 492, 3729, and 1510, respectively. Degree of pectin methylation of each sample was 76.0\% (HMP), 21.2\% (SBP), and $22.8 \%$ (SOY). Total SCFAs in SOY showed the highest value compared to other samples, especially having the highest concentration of propionic acid $(P<0.05)$. While fermentation with FOS showed higher butyrate production, the total SCFAs with SOY, HMP, and SBP were significantly higher than FOS over $30 \mathrm{~h}(\mathrm{P}<\mathbf{0 . 0 5})$. From the denaturing gradient gel electrophoresis (DGGE) analysis, changes of microbiota composition were found. In conclusion, pectin samples, especially soy pectin, stimulated production of total SCFAs and composition of human fecal microbiota was modulated. Therefore, pectin samples may alter the composition of fecal microbiota and improve the colonic health.
\end{abstract}

\section{Keywords}

Short-Chain Fatty Acids, Soy Pectin, Denaturing Gradient Gel Electrophoresis

\section{Introduction}

Colonic health has been reported to maintain overall health and reduce the risks of various diseases related to "Corresponding author.

How to cite this paper: Min, B., Koo, O.K., Park, S.H., Jarvis, N., Ricke, S.C., Crandall, P.G. and Lee, S.-O. (2015) Fermentation Patterns of Various Pectin Sources by Human Fecal Microbiota. Food and Nutrition Sciences, 6, 1103-1114. 
changes in nutrition and lifestyle. The human colon is closely involved with bacterial fermentation activities. The bacteria in the colon obtain energy for growth by fermenting carbohydrates in the colonic lumen, especially polysaccharides of plant cell walls (dietary fiber) and some starch. As concerns related to colonic health have become greater, functional ingredients have received attention. For example, dietary fiber, pectin substances, prebiotics, probiotics, and other dietary components that are capable of influencing the colon and its environment are widely used for various purposes and increase short-chain fatty acid (SCFA) production.

SCFAs, including acetate, propionate, and butyrate, are metabolites of the anaerobic bacterial fermentation of unabsorbed carbohydrates in the human intestine. SCFAs have a number of general actions to promote large bowel function [1]-[3]. Previous studies reported that SCFAs produced by anaerobic bacteria beneficially associate with inflammatory disease [4] [5]. In order to determine SCFAs produced by microbiota, in vitro fermentation analyses have been used to evaluate the fermentability of substrates within the gastrointestinal tracts of human.

Prebiotics are a selectively fermented ingredient that allows specific changes in composition and activity of the gastrointestinal microbiota to confer benefits to the host's well-being and health [6]. It is clear that fructooligosaccharide (FOS) and oligosaccharides stimulate Bifidobacterium and Lactobacillus which are known as beneficial microbiota and are common targets for dietary intervention [7] [8].

Dietary fiber (DF) is divided into two different fibers: insoluble and soluble fibers. Insoluble fibers (e.g., lignins, cellulose and some hemicellulose), which are limited to fermentation by colonic microbiota, play a pivotal role in fecal bulking and may carry with them fermentable carbohydrate substrates, including starches and sugars [9]. Soluble fibers (e.g., pectins, gums, mucilages, and some hemicelluloses) are fermented mainly by colonic microbiota [10].

Pectin plays an important role in food processing as a food additive and source of DF. It is also used as ingredients in the prevention of coronary heart disease, colon cancer, hypercholesterolemia [11]-[14]. Physiological (fermentability by microbiota) and functional properties (gelation or biding of metal ions) of pectin are different, relying on its structural parameters like molecular weight, degree of methylation (DM), and distribution of free and methoxylated carboxyl groups within the galacturonan chains [15]. Few studies have been investigated the effects of purified pectin on fermentation pattern and gut microbiota. The present study was designed to compare the effects of different pectin sources on changes of SCFA production and to measure the changes in the community profiles of the fecal microbiota.

\section{Materials and Methods}

\subsection{Chemicals and Materials}

All chemicals: acetic acid (99.9\% of purity), propionic acid (99.6\%), butyric acid (99.8\%), 4-methyl valeric acid (internal standard), acetone ( $>99.5 \%$, GC grade), metaphosphoric acid, alchol oxidase (from Pichiapastoris), Tris (Trizma grade), D-(+)-galacturonic acid, sodium chloride, sulfamic acid, formaldehyde, 3-methyl-2-benzothiazolinone hydrazine (MBTH), ammonium iron sulfate dodecahydrate, sulfuric acid, 3,5 dimethylphenol (DMP) and copper sulfate were purchased from Sigma-Aldrich (Sigma Chemical Co., St Louis, MO). Fructooligosaccharides (FOS) powder was provided by GTC Nutrition (Golden, CO, USA). Two pectins, HMP (high methoxy pectin) and SBP (sugar beet pectin), were kindly obtained from Tic Gums (Belcamp, MD, USA) and Herbstreith \& Fox (Elmsford, N.Y., USA), respectively. Soy pectin (SOY) was prepared according to Crandall \& McCain [16].

\subsection{Characterization of Pectin}

Galacturonic acid was released after acid hydrolysis of pectin samples. Total galacturonic acid was determined using a modified DMP (3,5dimethylphenol) method [17] with a maximum absorbance of $450 \mathrm{~nm}$. A modified AO/MBTH method [18] was used to determine the degree of methylation of pectin samples. Each pectin sample $(1 \mathrm{mg})$ was dissolved into a mixture that contained $700 \mu \mathrm{L}$ of $20 \mathrm{mM}$ Tris-HCl buffer (pH 7.5), $100 \mu \mathrm{L}$ of MBTH (dissolved in water at $3 \mathrm{mg} / \mathrm{mL}$ ) and $100 \mu \mathrm{L}$ of $0.5 \mathrm{M} \mathrm{NaCl}$ solution. The mixture reacted with alcohol oxidase (1 unit) at $30^{\circ} \mathrm{C}$ for $30 \mathrm{~min}$ for full digestion. A $200 \mu \mathrm{L}$ aliquot of acidic iron solution was added after digestion. After $30 \mathrm{~min}$, absorbance was determined using spectrophotometer (DU 520, Beckman Coulter, Brea, Calif., USA) at $620 \mathrm{~nm}$. The molecular weight distribution of the pectin samples was determined by high-per- 
formance size-exclusion chromatography on a series ShodexOHpak columns (KB-802, and KB-804) with HPLC system (Waters, Miliford, MA) that consisted of a 515 HPLC pump and 2410 refractive index detector [19].

\subsection{Subjects}

The study was reviewed and approved by the Institutional Review Board (IRB) at the University of Arkansas. Due to the limitation of soy pectin (SOY) material, four subjects were selected from University of Arkansas and the surrounding Fayetteville area. Dietary and health/medical questionnaires and informed consent forms were obtained from each participant before the sample collection. Fecal samples were collected from 4 male participants (23 to 28 years of age) who had been on a routine diet and not taken any antibiotics or medicine for 6 months prior to the study. Average energy and dietary fiber intakes of participants was processed with Nutritionist Pro (Version 4.4.0, Axxya system). Each fresh fecal sample was collected in in Commode Specimen Collection System (Fisher Scientific, Waltham, MA).

\subsection{Fecal Incubation}

An in vitro incubation was conducted to evaluate the fermentability of four substrates (FOS as a control, HMP, SBP and SOY) by human fecal bacteria. Two grams of fecal samples were added to $22 \mathrm{~mL}$ of sterile brain heart infusion (BHI) media. The BHI media (Difco Laboratories, Detroit, MI) was prepared according to Zheng et al. [20]. Tubes were incubated for each sample as well as a blank (BHI + feces). All steps for fermentation were conducted in an anaerobic chamber (Coy Laboratory Products Inc., Grass Lake, MI). The mixture was homogenized by vortexing right before incubation $\left(37^{\circ} \mathrm{C}\right)$. Four milliliters were taken using a sterile syringe from each tube immediately for time 0 and stored at $-20^{\circ} \mathrm{C}$. Subsequent aliquots were obtained at $6,12,24$, and $30 \mathrm{~h}$ and stored at $-20^{\circ} \mathrm{C}$ until analysis.

\subsection{SCFA Analysis}

To make a standard curve, a standard solution containing the three SCFAs were prepared by mixing $100 \mu \mathrm{L}$ of 4-methyl valeric acid $(50 \mathrm{mM})$ of the internal standard and diluting with acetone. Sample aliquots were thawed in room temperature and centrifuged at $3500 \times \mathrm{g}$ for $15 \mathrm{~min}$. After centrifugation, $0.5 \mathrm{~mL}$ of each aliquot and SCFA standards were mixed with $100 \mu \mathrm{L}$ of a mixture containing $50 \mathrm{mM}$ of 4-methyl-valeric acid (Internal Standard), 5\% meta-phosphoric acid, and copper sulfate $(1.56 \mathrm{mg} / \mathrm{mL})$. Each tube was centrifuged at 11,000 $\times \mathrm{g}$ for $10 \mathrm{~min}$ after reacting with the mixture for $10 \mathrm{~min}$ and stored at $-20^{\circ} \mathrm{C}$ until analysis. SCFA contents was analyzed in a gas chromatograph (Shimadzu GC-2010; Shimadzu Scientific Instruments, Columbia, MD) equipped with a flame ionization detector and using a fused silica capillary column (ID-BP21; SGE, L: 30 m, I.D: 0.25 $\mathrm{mm}$, Film: $25 \mu \mathrm{m}$, Ringwood, Victoria, Australia). The oven temperature was increased by $4^{\circ} \mathrm{C} / \mathrm{min}$ from $100^{\circ} \mathrm{C}$ ( $2 \mathrm{~min}$ ) to $120^{\circ} \mathrm{C}(1 \mathrm{~min})$, then at $3^{\circ} \mathrm{C} / \mathrm{min}$ until $150^{\circ} \mathrm{C}$. Hydrogen was used as the carrier gas. The sample injection $(1 \mu \mathrm{L})$ was performed in the split mode (30:1). The concentrations of acetic acid, propionic acid, and butyric acid were calculated from the calibration curves of each SCFA standards.

\subsection{DNA Extraction from Fecal Incubation}

Bacterial DNA was extracted using QIAamp DNA stool kit (QIAGEN, Valencia, CA). An aliquot (250 mg) of fecal sample was lysed using Garnet beads (MO BIO, Carlsbad, CA) and the lysed sample was centrifuged at $3000 \times \mathrm{g}$ for $1 \mathrm{~min}$. The sample was further vortexed for $10 \mathrm{~min}$ and incubated at $95^{\circ} \mathrm{C}$ for $6 \mathrm{~min}$. After incubation, the sample was centrifuged at 16,100 $\times \mathrm{g}$ for $1 \mathrm{~min}$. Eluted DNA was further processed for PCR procedures.

\subsection{DNA Amplification}

All DNA was amplified using touchdown PCR. Bacterial DNA amplification and denaturing gradient gel electrophoresis (DGGE) procedure were performed according to Hanning and Ricke [21]. A 233 bp portion of the 16s rRNA gene was amplified by PCR using primers of DGGE-F (5-CGC CCG CCG CGC GCG GCG GGC GGG GCG GGG GCA CGG GGG GCCTAC GGG AGG CAG CAG -3) and DGGE-R (5-ATT ACC GCG GCT GCT GG-3) (Integrated DNA Technologies, Coralville, IA) [22]. The touchdown PCR program was: ini- 
tial denaturation at $95^{\circ} \mathrm{C}$ for $2 \mathrm{~min}$, then 17 cycles of 1 ) denaturation at $94^{\circ} \mathrm{C}$ for $1 \mathrm{~min}$; 2) annealing at $67^{\circ} \mathrm{C}$ for $45 \mathrm{~s}$ decreasing by $-0.5^{\circ} \mathrm{C}$ per cycle to a touchdown temperature of $59^{\circ} \mathrm{C}$ and 3) annealing at $72^{\circ} \mathrm{C}$ for 2 min. The reaction was followed with 12 cycles of 4) denaturation at $94^{\circ} \mathrm{C}$ for $1 \mathrm{~min}$; 5) annealing at $58^{\circ} \mathrm{C}$ for $45 \mathrm{~s}$ with a final elongation step at $72^{\circ} \mathrm{C}$ for $7 \mathrm{~min}$. PCR product obtained was confirmed by $0.8 \%$ agarose gel electrophoresis with ultraviolet transillumination using the Quantity One software (Bio-Rad Laboratories, Richmond, CA).

\subsection{Gel Electrophoresis}

The $8 \%$ polyacrylamide gels (acrylamide:bisacrylamide $=37: 1$ ) consisted of a 35\% to $60 \%$ of urea-deionized formamide gradient; the $100 \%$ denaturing acrylamide was composed of $7 \mathrm{M}$ urea and $40 \%$ deionized formamide. The equal concentration of PCR product $(2 \mu \mathrm{g})$ was mixed with loading buffer $[0.05 \%$ bromophenol blue (w/v); 0.05\% xylene cyanol $(\mathrm{w} / \mathrm{v})$; and $70 \%$ glycerol $(\mathrm{v} / \mathrm{v})]$ and the mixed samples were loaded in each well. Electrophoresis was carried out in a D-Code Universal Mutation Detection System (Bio-Rad Laboratories) in TAE (Tris-acetate-EDTA) buffer (1 mM EDTA, $20 \mathrm{mM}$ acetic acid, $40 \mathrm{mM}$ Tris) at $59^{\circ} \mathrm{C}$ for $17 \mathrm{~h}$ at $60 \mathrm{~V}$. The gels were stained with SYBR Green (1:50,000 dilution, Cambrex Bioscience, Walkersville, MD) in TAE for 40 min and the result was observed with ultraviolet transillumination for image acquisition.

\subsection{DNA Extraction and Sequence Analysis}

Bands of interest were excised from the DGGE (Denaturing Gradient Gel Electrophoresis) gel using a previous protocol [23]. The extracted DNA was sequenced in the DNA Resource Center at the University of Arkansas (Fayetteville, AR) using an ABI 3100 capillary analyzing system (Applied Biosystems, Foster City, CA) and the sequences were compared with the GenBank database using the Blast algorithm. For showing phylogenetic analysis, UPGMA’s method was used for the analysis using Bio-rad quantity One (software ver. 4.6.7).

\subsection{Statistical Analysis}

Statistical analysis was carried out by statistical program: SAS 9.4 (SAS Inst., Cary, N.C., USA), using either 1) one-way ANOVA when comparing three or more data sets or 2) a t test when comparing two data sets. All data are presented as mean \pm S.E.M (Standard Error of Mean). Differences were deemed significant when $\mathrm{P}<$ 0.05 .

\section{Results and Discussion}

\subsection{Subject Profile and Nutrient Intakes}

Table 1 shows the participant information including age, body mass index (BMI), average daily calorie, and dietary fiber intake. The BMI of subject 4 was within the normal range (18.5 - 24.9), in contrast, subject 1 through 3 were overweight (25.0 to 29.9). The US Department of Agriculture recommends men consume 2000 to 2600 calories if they are sedentary, 2200 to 2800 calories if they are moderately active. In this study, all of subjects consumed less than 2000 kcal of energy.

Evidence has been firmly established that consuming recommended dietary fiber (25 - 35 g/day) exerts a beneficial influence on human colonic health and provides many health benefits such as preventing coronary heart disease, stroke, hypertension, diabetes and obesity [24] [25]. In addition, long-term dietary fiber intake is

Table 1. Participant information.

\begin{tabular}{|c|c|c|c|c|}
\hline Subject & Age & $\underset{\left(\mathrm{Kg} / \mathrm{m}^{2}\right)}{\mathrm{BMI}}$ & $\begin{array}{c}\text { Average daily energy } \\
\text { (Kcal) }\end{array}$ & $\begin{array}{l}\text { Dietary fiber } \\
\text { (g/day) }\end{array}$ \\
\hline 1 & 23 & 27.8 & 1899 & 29.6 \\
\hline 2 & 28 & 26.2 & 1713 & 18.9 \\
\hline 3 & 21 & 28.0 & 1912 & 30.6 \\
\hline 4 & 28 & 19.2 & 1898 & 17.7 \\
\hline Average & $25 \pm 3.1$ & $25.3 \pm 3.6$ & $1856 \pm 82.5$ & $24.2 \pm 5.9$ \\
\hline
\end{tabular}

Average values are expressed as mean \pm SEM. 
associated with the number and composition of gut microbiota as well as reducing gut apoptosis [26] [27]. Subject 1 and 3 consumed close to $30 \mathrm{~g}$ daily, while subject 2 and 4 (18.9 g and $17.7 \mathrm{~g}$, respectively) consumed less than the recommended daily intake of dietary fiber. It is presumed that the gut microbiota from subject 1 and 3 might have greater availability to use dietary fiber than the individuals who consumed the lower level of dietary fiber (subject 2 and 4). Lesser availability of dietary fiber might be one of the fundamental reasons for lower production of SCFAs.

\subsection{Characteristic of Samples}

The average degree of polymerization (DP) of pectin samples was determined using an HPLC system; SOY1510, SBP-3729, HMP-492 (Figure 1). Also, the degree of pectin methylation (DM, \%) of each sample was determined as $22.8 \%$ (SOY), $21.2 \%$ (SBP), and 76.0\% (HMP), respectively. SOY and SBP were determined as low-methoxypectins (LMP, DM $<50 \%$ ). As shown in Figure 1, the HPLC profile of SBP and SOY exhibited a similar pattern, while the HPLC profile of HMP responded differently.

Intrinsic factors such as DP, DM, and chain length are key parameters affecting the behavior of pectin [28]. There are only few studies that have compared bioavailability or health effects between pectin with different chemical characteristics (DP and DM), source, and type. Citrus pectin sources (high DM and high MW) exerted greater LDL cholesterol-lowering properties than low DM and low MW of citrus pectin and high DM of orange pulp fiber [29]. However, Judd and Truswell [30] reported that LMP has similar cholesterol-lowering effects compared to HMP. Wet and dry weights of feces were higher on HMP, while gut transit time and fecal water were similar in both groups (HMP and LMP). With even limited evidence from previous studies, differences with DP and DM of pectin samples might have different fermentability by human gut microbiota and bioavailability for human health.

\subsection{Short-Chain Fatty Acid Analysis}

Production of SCFAs can be stimulated with dietary fiber. Titgemeyer et al. [31] found that fermentation with citrus and apple pectin increased the SCFAs more than fiber sources from sugar beet and oat. In the present study, total SCFAs production of subjects with samples is shown in Table 2. These values were calculated for the sum of SCFAs: acetate, propionate, and butyrate. Each pectin sample had different patterns for production of SCFAs. Specifically, fermentation with SOY showed significantly higher propionate production $(\mathrm{P}<0.05)$. FOS showed the highest butyrate production during $30 \mathrm{hrs}$.

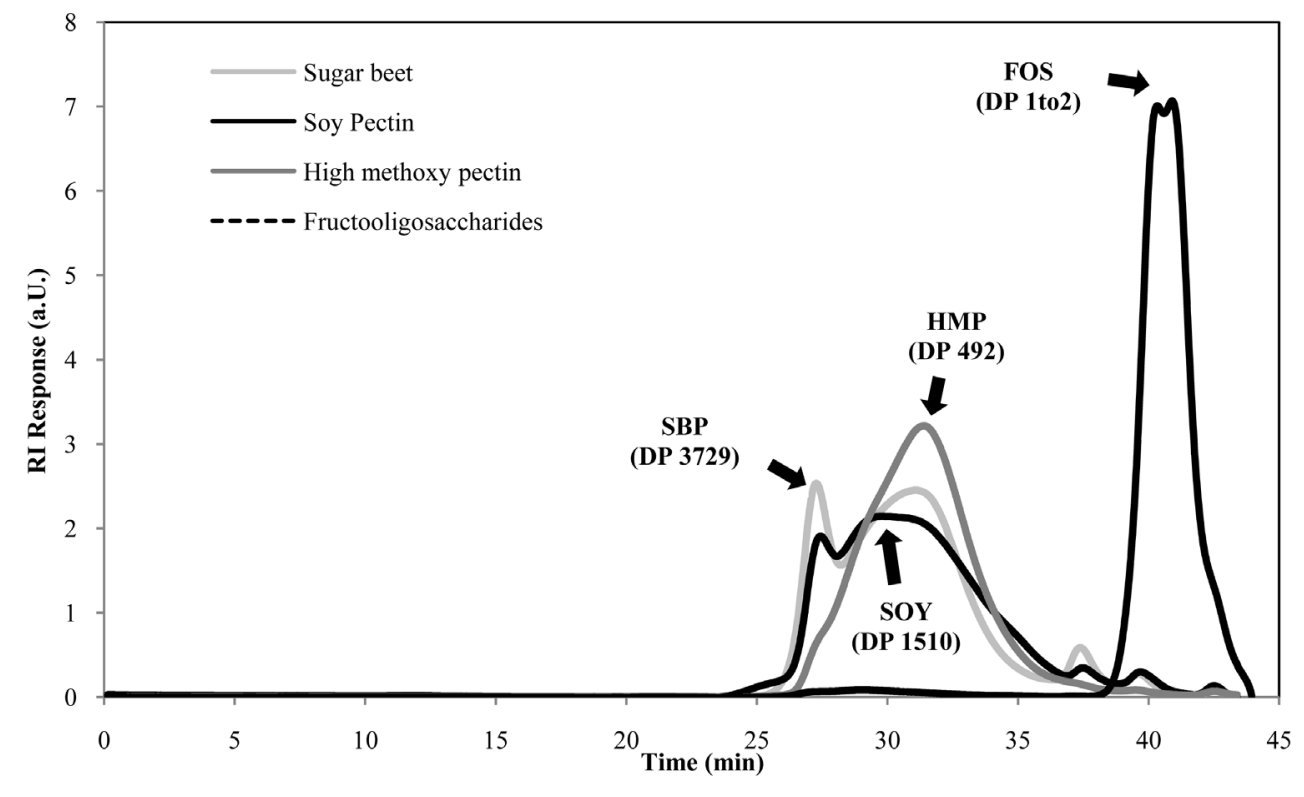

Figure 1. Chromatogram of pectins and FOS using RI detector. HMP = High Methoxy Pectin; SBP = Suger Beet Pectin; FOS = Fructooligosaccharides; SOY = Soy Pectin. 
Table 2. Net production of SCFAs during in vitro incubation with human feces.

\begin{tabular}{ccccc}
\hline $\begin{array}{c}\text { SCFAs } \\
(\mathrm{mM} / 0.5 \mathrm{~g} \text { of sample) }\end{array}$ & FOS & HMP & SBP & SOY \\
\hline $\begin{array}{c}\text { Acetate } \\
\text { Propionate }\end{array}$ & $10.7 \pm 6.9^{\mathrm{b}}$ & $70.6 \pm 5.0^{\mathrm{a}}$ & $75.0 \pm 5.3^{\mathrm{a}}$ & $64.1 \pm 3.1^{\mathrm{a}}$ \\
Butyrate & $16.2 \pm 2.9^{\mathrm{b}}$ & $9.1 \pm 1.1^{\mathrm{c}}$ & $14.0 \pm 1.2^{\mathrm{b}}$ & $35.2 \pm 1.7^{\mathrm{a}}$ \\
Toal SCFAs & $36.2 \pm 1.1^{\mathrm{a}}$ & $18.1 \pm 2.2^{\mathrm{b}}$ & $13.1 \pm 3.0^{\mathrm{b}}$ & $31.1 \pm 3.4^{\mathrm{a}}$ \\
\hline
\end{tabular}

Values are expressed as mean + SEM. Superscripts not sharing a common letter within the same row are significantly different among groups at $\mathrm{P}<$ 0.05. FOS: fructooligosaccharides; HMP: high methoxy pectin; SBP: sugar beet pectin; SOY: soy pectin.

All pectin samples (HMP, SBP, and SOY) showed higher acetate production than fermentation without substrate (Figure 2(A)) $(\mathrm{P}<0.05)$. Acetate, the principal SCFA in the colon, is readily absorbed and transported to the liver, and therefore less metabolized in the colon [32]. In addition, acetate can be used as a source for butyrate. Diez-Gonzalez et al. [33] reported two different mechanisms (acetate utilization and lactate fermentation) and enzymes (butyrylCoA:acetate CoA transferase and butyrate kinase) that are important factors for production of butyrate in the gut. Also, Coprococcus sp., Roseburia sp., R. intestinals, and Facalibacteriumprausnitzii are known as bacteria that can convert butyrate, using acetate [34]. Acetate is often used to monitor colonic events because it is the primary SCFA. Also, increasing the concentration of acetate resulted in lowering $\mathrm{pH}$; this reaction might be related to the beneficial influence on the composition of gut microbiota and preventing the proliferation of harmful species and growth of pathogenic bacteria.

The production of propionic acid during in vitro fermentation (30 h) is illustrated in Figure 2(B). Fermentation with SOY demonstrated significantly higher propionate production than other pectin samples (HMP and $\mathrm{SBP}$ ) and FOS during 30 hrs $(\mathrm{P}<0.05)$. Propionate has been shown to lower glucose-induced insulin secretion in isolated pancreatic islet cells of rats [35]. It is also reported that propionate has anti-proliferative effect towards colon cancer [36] [37] and is related to weight control and feeding behavior [38] [39].

Butyrate is the preferred energy source of colonocytes; approximately $70 \%$ to $90 \%$ of butyrate is metabolized by the colonocytes. Various studies have found that butyrate has a positive effect in the prevention of colon cancer [3] [36] [40]. Diez-Gonzalez et al. [33] reported that butyrate is formed from two molecules of acetyl coenzyme A that yields acetoacetyl-CoA, which is converted into butyryl-CoA. Consequently, butyryl-CoA might yield butyrate through butyrate kinase by some butyrate-producing strains such as Butyrivibriofibrisolvens or via butyryl-CoA: acetate-CoA transferase. Compared to other SCFAs, concentration of butyrate increased at later time point than other SCFAs (Figure 2(C)). According to Duncan's study [41], butyrate can be converted, as gut microbiota consumes acetate. Thus, current result implies production of SCFAs also might be affected by other SCFAs and SCFAs can be changed interdependently in anaerobic fermentation.

\subsection{DGGE Experiment}

The human intestinal microbiota has been known to contain complicated colonies composed of at least several hundred different species of bacteria with approximately $10^{11}$ to $10^{12}$ cells per gram of feces [42] [43].

Based on DGGE results, Figure 3 and Table 3 show patterns of each subject, excised bands number and identifications. In this study, all subjects had very diverse gut microbiota. Even though most of the sequences of bands were assigned to uncultured bacterium or were not identified, Table 3 shows the dominant strains indicated by the banding patterns.

Microbial metabolites, potential growth factors in fecal material, and dietary habit are important factors to affect the composition of gut microbiota. In the present study, Firmicutes species, Faecalibacterium species, Bacteroides species that have been regarded dominant human fecal bacterium were detected in subjects 1 to 4 . The band of Firmicutes species was enriched after exposure to dietary FOS, SBP and HMP from subject 1 as well as FOS with subject 3. While Firmicutes species were detected from subject 1 and 3, the band of Firmicutes species was not detected in subjects 2 and 4. DGGE bands for fecalibacterium species were detected in subjects 1, 3, and 4 . The band identified as fecalibacterium was present in all samples and the blank from subjects 1, 3, and 4 . Bacteroides was present in subject 2 and 3. These three strains: Firmicutes species, Faecalibacterium species, and Bacteroides species were reported to be related to the production of SCFAs and host health. According to Shen's study, Bacteroides numbers may correlate with the increase in propionate production [44]. The number of dominant fecal bacterium is changed by disease status or body weight [45] [46]. Schwiertz et al. [47] reported 


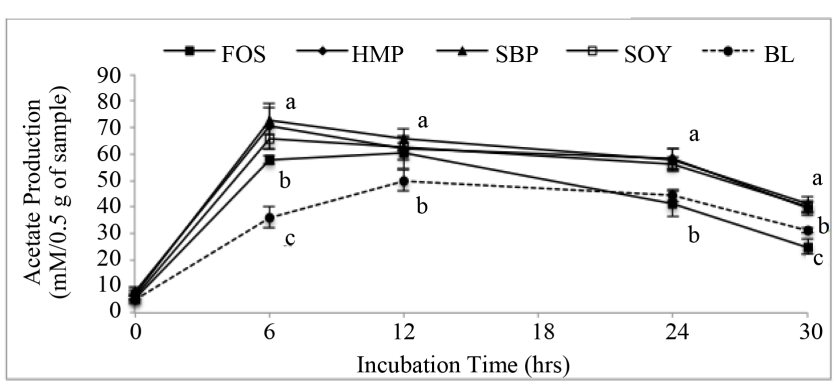

(A)

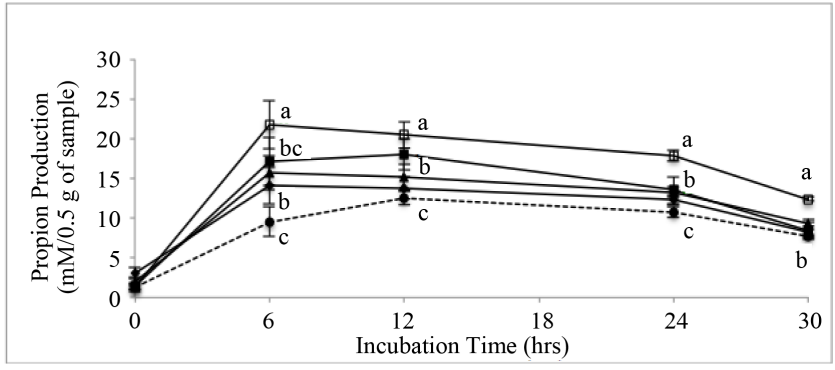

(B)

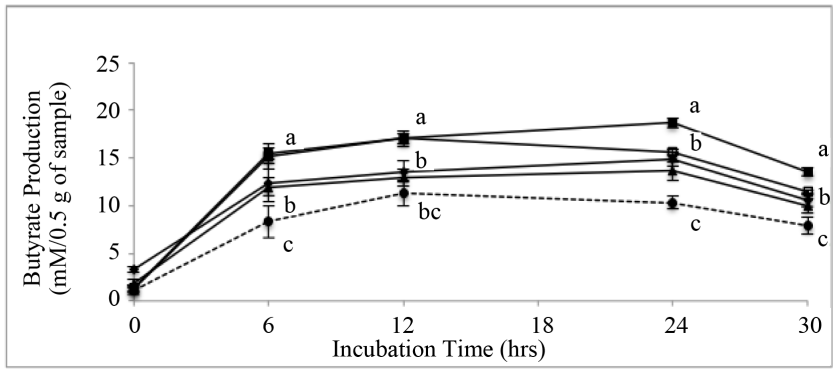

(C)

Figure 2. SCFAS produced during in vitro fecal fermentation (30 hours). (A) Acetate production; (B) Propionate production; (C) Butyrate production; FOS = fructooligosaccharides; HMP = high methoxy pectin; $\mathrm{SBP}=$ sugar beet pectin; $\mathrm{SOY}=$ soy pectin; $\mathrm{BL}=$ blank. Different letters at the same incubation time indicate statistical significant difference $(\mathrm{P}<0.05)$.

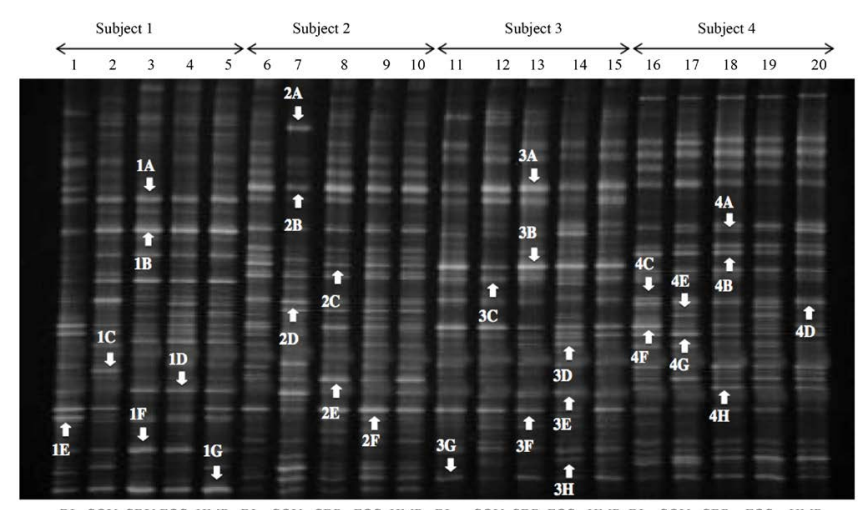

BL SOY SBY FOS HMP BL SOY SBP FOS HMP BL SOY SBP FOS HMP BL SOY SBP FOS HMP

Figure 3. Denaturing gradient gel elecrophoresis (DGGE) banding patterns of 16S rRNA gene fragments generated from bacterial DNA isolated from fecal batch after 30 hours incubation. BL = blank; SOY = soy pectin; SBP = sugar beet pectin; FOS = fructooligosaccharides; HMP = high methoxy pectin. 
Table 3. Homology of excised denaturing gradient gel electrophoresis (DGGE) amplicons with previously reported species and phylotypes.

\begin{tabular}{|c|c|}
\hline Band Number & Bacteria \\
\hline $1 \mathrm{~A}, \mathrm{~B}$ & Uncultured bacterium \\
\hline $1 \mathrm{C}$ & Lactobacillus ruminis \\
\hline $1 \mathrm{D}$ & Faecalibacterium species \\
\hline $1 \mathrm{E}$ & Uncultured Catenibacterium species \\
\hline $1 \mathrm{~F}$ & Prevotella bergensis \\
\hline $1 \mathrm{G}$ & Uncultured Firmicutes bacterium \\
\hline $2 \mathrm{~A}$ & Coprobacillus cateniformis \\
\hline 2B & Bacteroidesspecies \\
\hline $2 \mathrm{C}$ & Alistipes species \\
\hline $2 \mathrm{D}$ & Eubacterium eligens \\
\hline $2 \mathrm{E}$ & Uncultured Ruminococcaceae bacterium \\
\hline $2 \mathrm{~F}$ & Thermaerobacter marianensis \\
\hline $3 \mathrm{~A}$ & Bacteroidesspecies \\
\hline 3B & Catonella species \\
\hline 3C & Uncultured Ruminococcaceae bacterium \\
\hline $3 \mathrm{D}$ & Faecalibacterium prausnitzii \\
\hline $3 \mathrm{E}$ & Uncultured Firmicutes bacterium \\
\hline $3 \mathrm{~F}$ & Uncultured Clostridiales bacterium \\
\hline $3 G$ & Uncultured Bifidobacterium species \\
\hline $3 \mathrm{H}$ & Dialister succinatiphilus \\
\hline $4 \mathrm{~A}$ & Faecalibacterium prausnitzii \\
\hline 4B & Uncultured bacterium \\
\hline $4 \mathrm{C}$ & Pseudobutyrivibrio species \\
\hline 4D & Uncultured Bacteroidales bacterium \\
\hline $4 \mathrm{E}$ & Uncultured Bifidobacterium species \\
\hline $4 \mathrm{~F}$ & Faecalibacterium prausnitzii \\
\hline 4G & Coprococcus species \\
\hline $4 \mathrm{H}$ & Uncultured Barnesiellaspecies \\
\hline
\end{tabular}

that the ratio of Firmicutes to Bacteroidetes altered in favor of the Firmicutes in overweight and obese subjects.

Interestingly, specific bacteria were also detected from each subject. Lactobacillus rumis is one of the dominant Lactobacillus species that have been known as probiotics. L. rumis showed positive effects on human colonic health, such as inhibition of pathogenic microorganisms and relief of lactose maldigestionsymtoms [48]. In subject 1 , the band for $L$. rumis was found to be most intense with soy pectin sample (SOY). Based on this result, soy pectin might have a positive effect on the growth of L. rumis. The band of Bifidobacterium species was found in subject 3 and 4, fermentation with SBP or without substrates. Pseudobutyrivibrio species were also detected in subject 4. The bands of Pseudobutyrivibrio specises in subject 4 were enriched with fermentation of all pectin samples and FOS, except Blank. This strain has been reported that it is closely related to butyric acid production [49].

From analysis of SCFAs, all pectin samples showed higher butyrate production. This result might be thought that pectin samples and FOS stimulate growth of Pseudobutyrivibrio specises and subsequently metabolize more butyrate production.

In order to compare composition of microbiota fermented with different samples by each subject, analysis with the phylogenetic trees is shown and illustrated the correlation between samples and subjects (Figure 4). The phylogenetic trees of samples generated by the UPGMA algorithm exhibited 5 different groups in each treatment. Subject 4 can be categorized as a normal weight person, while other subjects are considered as overweight. From phylogenetic analysis with bands from samples fermented without substrates (BL) it appears that subjects 4 and subject 2 (lower dietary fiber intake) are clustered with $70 \%$ of relatedness. Also, subject 4 was clustered with subject 3 (65\%) and subject 1 (64\%), respectively. This result indicates that subject 4 and subject 2 have similar pattern of microbiota, than the other subjects. This pattern was also detected with FOS and SBP samples. However, samples fermented with SOY and HMP exhibited different patterns compared to the blank. In particular, the relatedness was decreased by fermentation with the respective samples. Even if same source was utilized for fermentation, the composition of microbiota became more diverse due to the difference of initial 

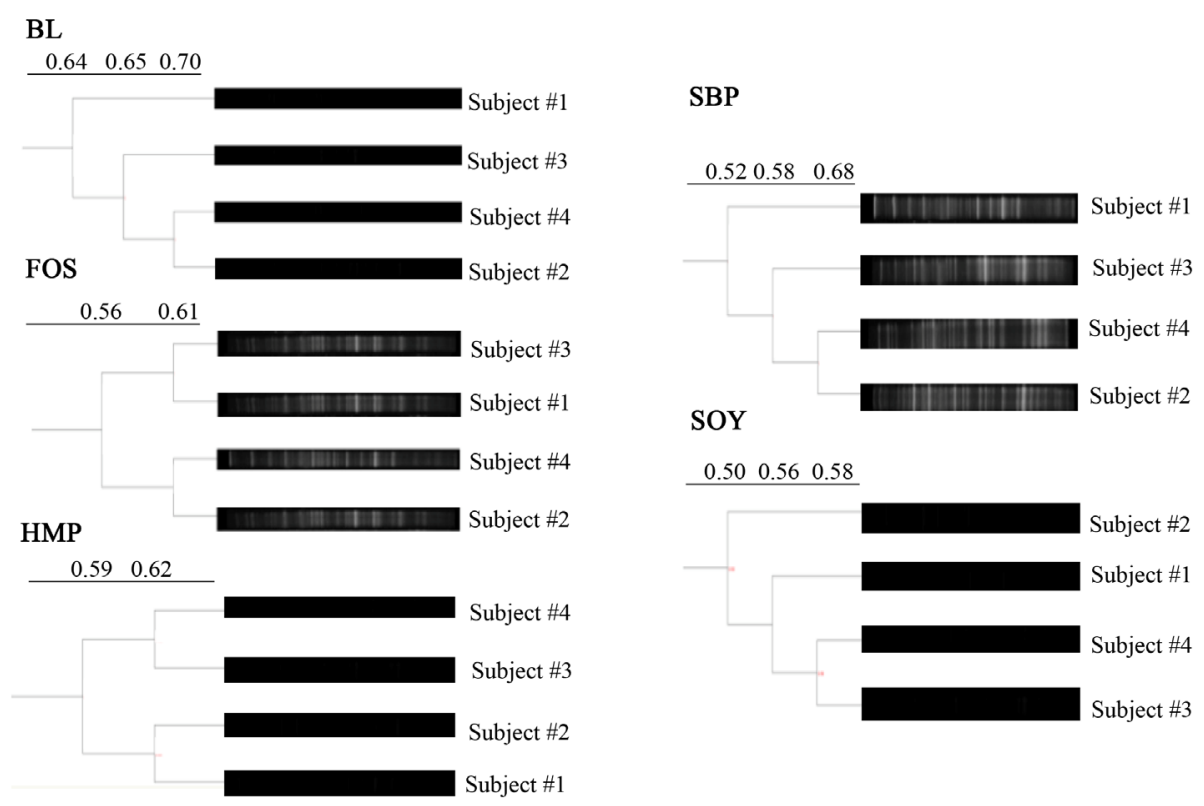

Figure 4. Phylogenetic tree based on denaturing gradient gel electrophoresis (DGGE) results. $\mathrm{BL}$ = blank; FOS = fructooligosaccharides; HMP = high methoxy pectin; $\mathrm{SBP}=$ sugar beet pectin; $\mathrm{SOY}=$ soy pectin; $\mathrm{BL}=$ blank.

microbiota composition of subjects. This result implies that composition of microbiota can be altered by substrates, but ecology of microbiota did not change significantly during $30 \mathrm{~h}$ of fermentation, because each subject had a different composition of microbiota at the beginning.

The current study investigated the changes in microbiota during in vitro fermentation. Even though no relationships between specific species and pectin samples were determined due to the limitation of the DGGE experiment, the data demonstrated that pectin samples showed different fermentation patterns. Further study could validate this with quantification to determine the specific microbiota related to SCFA production.

\section{Conclusion}

All pectin samples showed higher total SCFAs production compared to FOS. In particular, SOY increased the production of butyric acid and propionic acid. Furthermore, fermentation by human fecal microbiota with pectin samples might modulate profiles of microbiota. Pectin samples coming from different sources have different characteristics to produce microbial metabolites and to affect the composition of gut microbiota.

\section{Acknowledgements}

The study was supported by the Arkansas Soybean Promotion Board.

\section{References}

[1] Topping, D. (2007) Cereal Complex Carbohydrates and Their Contribution to Human Health. Journal of Cereal Science, 46, 220-229. http://dx.doi.org/10.1016/j.jcs.2007.06.004

[2] Topping, D.L. and Clifton, P.M. (2001) Short-Chain Fatty Acids and Human Colonic Function: Roles of Resistant Starch and Nonstarch Polysaccharides. Physiological Reviews, 81, 1031-1064.

[3] Bornet, F., Brouns, F., Tashiro, Y. and Duvillier, V. (2002) Nutritional Aspects of Short-Chain Fructooligosaccharides: Natural Occurrence, Chemistry, Physiology and Health Implications. Digestive and Liver Disease, 34, S111-S120. http://dx.doi.org/10.1016/s1590-8658(02)80177-3

[4] Kurita-Ochiai, T., Fukushima, K. and Ochiai, K. (1995) Volatile Fatty Acids, Metabolic By-Products of Periodontopathic Bacteria, Inhibit Lymphocyte Proliferation and Cytokine Production. Journal of Dental Research, 74, 13671373. http://dx.doi.org/10.1177/00220345950740070801

[5] Vinolo, M., Rodrigues, H., Hatanaka, E., Hebeda, C., Farsky, S. and Curi, R. (2009) Short-Chain Fatty Acids Stimulate 
the Migration of Neutrophils to Inflammatory Sites. Clinical Science, 117, 331-338. http://dx.doi.org/10.1042/CS20080642

[6] Gibson, G.R., Probert, H.M., Van Loo, J., Rastall, R.A. and Roberfroid, M.B. (2004) Dietary Modulation of the Human Colonic Microbiota: Updating the Concept of Prebiotics. Nutrition Research Reviews, 17, 259-275. http://dx.doi.org/10.1079/NRR200479

[7] Kajiwara, S., Gandhi, H. and Ustunol, Z. (2002) Effect of Honey on the Growth of and Acid Production by Human Intestinal Bifidobacterium spp.: An in Vitro Comparison with Commercial Oligosaccharides and Inulin. Journal of Food Protection, 65, 214-218.

[8] Manning, T.S. and Gibson, G.R. (2004) Prebiotics. Best Practice \& Research Clinical Gastroenterology, 18, $287-298$. http://dx.doi.org/10.1016/j.bpg.2003.10.008

[9] Jenkins, D.J., Vuksan, V., Kendall, C.W., Wursch, P., Jeffcoat, R., Waring, S., Mehling, C.C., Vidgen, E., Augustin, L.S. and Wong, E. (1998) Physiological Effects of Resistant Starches on Fecal Bulk, Short Chain Fatty Acids, Blood Lipids and Glycemic Index. Journal of the American College of Nutrition, 17, 609-616. http://dx.doi.org/10.1080/07315724.1998.10718810

[10] Cummings, J.H. (1981) Short Chain Fatty Acids in the Human Colon. Gut, 22, 763-779. http://dx.doi.org/10.1136/gut.22.9.763

[11] Reiser, S. (1987) Metabolic Effects of Dietary Pectins Related to Human Health. Food Technology, 41, 91-99.

[12] Cerda, J.J. (1988) The Role of Grapefruit Pectin in Health and Disease. Transactions of the American Clinical and Climatological Association, 99, 203-213.

[13] Salman, H., Bergman, M., Djaldetti, M., Orlin, J. and Bessler, H. (2008) Citrus Pectin Affects Cytokine Production by Human Peripheral Blood Mononuclear Cells. Biomedicine \& Pharmacotherapy, 62, 579-582. http://dx.doi.org/10.1016/j.biopha.2008.07.058

[14] Nangia-Makker, P., Hogan, V., Honjo, Y., Baccarini, S., Tait, L., Bresalier, R. and Raz, A. (2002) Inhibition of Human Cancer Cell Growth and Metastasis in Nude Mice by Oral Intake of Modified Citrus Pectin. Journal of the National Cancer Institute, 94, 1854-1862. http://dx.doi.org/10.1093/jnci/94.24.1854

[15] Dongowski, G., Lorenz, A. and Proll, J. (2002) The Degree of Methylation Influences the Degradation of Pectin in the Intestinal Tract of Rats and in Vitro. Journal of Nutrition, 132, 1935-1944.

[16] Crandall, P.G. and McCain, A.M. (2000) Isolation and Characterization of Pectinaceous Substances from Soybean Byproducts. Journal of Food Processing and Preservation, 24, 407-422. http://dx.doi.org/10.1111/j.1745-4549.2000.tb00428.x

[17] Luzio, G.A. (2004) Determination of Galacturonic Acid Content of Pectin Using a Microtiter Plate Assay. Proceedings of the Florida State Horticultural Society, 117, 416-421.

[18] Anthon, G.E. and Barrett, D.M. (2004) Comparison of Three Colorimetric Reagents in the Determination of Methanol with Alcohol Oxidase. Application to the Assay of Pectin Methylesterase. Journal of Agricultural and Food Chemistry, 52, 3749-3753. http://dx.doi.org/10.1021/jf035284w

[19] Patindol, J.A., Gonzalex, B.C., Wang, Y-J. and McClung, A.M. (2007) Starch Fine Structure and Physicochemical Properties of Specialty Rice for Canning. Journal of Cereal Science, 45, 209-218. http://dx.doi.org/10.1016/j.jcs.2006.08.004

[20] Zheng, Y.L., Hu, J., Murphy, P.A., Alekel, D.L., Franke, W.D. and Hendrich, S. (2003) Rapid Gut Transit Time and Slow Fecal Isoflavone Disappearance Phenotype Are Associated with Greater Genistein Bioavailability in Women. Journal of Nutrition, 133, 3110-3116.

[21] Hanning, I.B. and Ricke, S.C. (2011) Prescreening of Microbial Populations for the Assessment of Sequencing Potential. In: Kwon, Y.M. and Ricke, S.C., Eds., High-Throughput Next Generation Sequencing, Springer, New York, 159170. http://dx.doi.org/10.1007/978-1-61779-089-8_11

[22] Muyzer, G., De Waal, E.C. and Uitterlinden, A.G. (1993) Profiling of Complex Microbial Populations by Denaturing Gradient Gel Electrophoresis Analysis of Polymerase Chain Reaction-Amplified Genes Coding for 16S rRNA. Applied and Environmental Microbiology, 59, 695-700.

[23] Salyer, J., Park, S.H., Ricke, S.C. and Lee, S.-O. (2013) Analysis of Microbial Populations and Metabolism of Anthocyanins by Mice Gut Microflora Fed with Blackberry Powder. Journal of Nutrition \& Food Sciences, 3, 1-5. http://dx.doi.org/10.4172/2155-9600.1000178

[24] Wallström, P., Sonestedt, E., Hlebowicz, J., Ericson, U., Drake, I., Persson, M., Gullberg, B., Hedblad, B. and Wirfält, E. (2012) Dietary Fiber and Saturated Fat Intake Associations with Cardiovascular Disease Differ by Sex in the Malmö Diet and Cancer Cohort: A Prospective Study. PLoS ONE, 7, e31637. http://dx.doi.org/10.1371/journal.pone.0031637

[25] Howarth, N.C., Saltzman, E. and Roberts, S.B. (2001) Dietary Fiber and Weight Regulation. Nutrition Reviews, 59, 
129-139. http://dx.doi.org/10.1111/j.1753-4887.2001.tb07001.X

[26] Wu, G.D., Chen, J., Hoffmann, C., Bittinger, K., Chen, Y-Y., Keilbaugh, S.A., Bewtra, M., Knights, D., Walters, W.A. and Knight, R. (2011) Linking Long-Term Dietary Patterns with Gut Microbial Enterotypes. Science, 334, 105-108. http://dx.doi.org/10.1126/science.1208344

[27] Nofrarías, M., Martínez-Puig, D., Pujols, J., Majó, N. and Pérez, J.F. (2007) Long-Term Intake of Resistant Starch Improves Colonic Mucosal Integrity and Reduces Gut Apoptosis and Blood Immune Cells. Nutrition, 23, 861-870. http://dx.doi.org/10.1016/j.nut.2007.08.016

[28] Thakur, B.R., Singh, R.K., Handa, A.K. and Rao, M. (1997) Chemistry and Uses of Pectin-A Review. Critical Reviews in Food Science and Nutrition, 37, 47-73. http://dx.doi.org/10.1080/10408399709527767

[29] Brouns, F., Theuwissen, E., Adam, A., Bell, M., Berger, A. and Mensink, R. (2011) Cholesterol-Lowering Properties of Different Pectin Types in Mildly Hyper-Cholesterolemic Men and Women. European Journal of Clinical Nutrition, 66, 591-599. http://dx.doi.org/10.1038/ejcn.2011.208

[30] Judd, P.A. and Truswell, A. (1982) Comparison of the Effects of High- and Low-Methoxyl Pectins on Blood and Faecal Lipids in Man. British Journal of Nutrition, 48, 451-458. http://dx.doi.org/10.1079/BJN19820130

[31] Titgemeyer, E.C., Bourquin, L.D., Fahey, G.C. and Garleb, K.A. (1991) Fermentability of Various Fiber Sources by Human Fecal Bacteria in Vitro. The American Journal of Clinical Nutrition, 53, 1418-1424.

[32] Cook, S.I. and Sellin, J.H. (1998) Review Article: Short Chain Fatty Acids in Health and Disease. Alimentary Pharmacology \& Therapeutics, 12, 499-507. http://dx.doi.org/10.1046/j.1365-2036.1998.00337.x

[33] Diez-Gonzalez, F., Bond, D.R., Jennings, E. and Russell, J.B. (1999) Alternative Schemes of Butyrate Production in Butyrivibrio fibrisolvens and Their Relationship to Acetate Utilization, Lactate Production, and Phylogeny. Archives of Microbiology, 171, 324-330. http://dx.doi.org/10.1007/s002030050717

[34] Duncan, S.H., Hold, G.L., Barcenilla, A., Stewart, C.S. and Flint, H.J. (2002b). Roseburia intestinalis sp. nov., a Novel Saccharolytic, Butyrate-Producing Bacterium from Human Faeces. International Journal of Systematic and Evolutionary Microbiology, 52, 1615-1620. http://dx.doi.org/10.1099/00207713-52-5-1615

[35] Ximenes, H., Hirata, A.E., Rocha, M.S., Curi, R. and Carpinelli, A.R. (2007) Propionate Inhibits Glucose-Induced Insulin Secretion in Isolated Rat Pancreatic Islets. Cell Biochemistry and Function, 25, 173-178. http://dx.doi.org/10.1002/cbf.1297

[36] Scheppach, W., Bartram, H. and Richter, F. (1995) Role of Short-Chain Fatty Acids in the Prevention of Colorectal Cancer. European Journal of Cancer, 31, 1077-1080. http://dx.doi.org/10.1016/0959-8049(95)00165-F

[37] Jan, G., Belzacq, A., Haouzi, D., Rouault, A., Metivier, D., Kroemer, G. and Brenner, C. (2002) Propionibacteria Induce Apoptosis of Colorectal Carcinoma Cells via Short-Chain Fatty Acids Acting on Mitochondria. Cell Death \& Differentiation, 9, 179-188. http://dx.doi.org/10.1038/sj.cdd.4400935

[38] Oba, M. and Allen, M.S. (2003) Intraruminal Infusion of Propionate Alters Feeding Behavior and Decreases Energy Intake of Lactating Dairy Cows. Journal of Nutrition, 133, 1094-1099.

[39] Ruijschop, R.M.A.J., Boelrijk, A.E.M. and te Giffel, M.C. (2008) Satiety Effects of a Dairy Beverage Fermented with Propionic Acid Bacteria. International Dairy Journal, 18, 945-950. http://dx.doi.org/10.1016/j.idairyj.2008.01.004

[40] Hague, A., Elder, D.J., Hicks, D.J. and Paraskeva, C. (1995) Apoptosis in Colorectal Tumour Cells: Induction by the Short Chain Fatty Acids Butyrate, Propionate and Acetate and by the Bile Salt Deoxycholate. International Journal of Cancer, 60, 400-406. http://dx.doi.org/10.1002/ijc.2910600322

[41] Duncan, S.H., Barcenilla, A., Stewart, C.S., Pryde, S.E. and Flint, H.J. (2002) Acetate Utilization and Butyryl Coenzyme A (CoA): Acetate-CoA Transferase in Butyrate-Producing Bacteria from the Human Large Intestine. Applied and Environmental Microbiology, 68, 5186-5190. http://dx.doi.org/10.1128/AEM.68.10.5186-5190.2002

[42] Carman, R., Van Tassell, R. and Wilkins, T. (1992) The Normal Intestinal Microflora: Ecology, Variability and Stability. Veterinary and Human Toxicology, 35, 11-14.

[43] Ley, R.E., Peterson, D.A. and Gordon, J.I. (2006) Ecological and Evolutionary Forces Shaping Microbial Diversity in the Human Intestine. Cell, 124, 837-848. http://dx.doi.org/10.1016/j.cell.2006.02.017

[44] Shen, Q., Tuohy, K., Gibson, G. and Ward, R. (2011) In Vitro Measurement of the Impact of Human Milk Oligosaccharides on the Faecal Microbiota of Weaned Formula-Fed Infants Compared to a Mixture of Prebiotic Fructooligosaccharides and Galactooligosaccharides. Letters in Applied Microbiology, 52, 337-343. http://dx.doi.org/10.1111/j.1472-765X.2011.03005.x

[45] Martín, R., Miquel, S., Ulmer, J., Kechaou, N., Langella, P. and Bermúdez-Humarán, L.G. (2013) Role of Commensal and Probiotic Bacteria in Human Health: A Focus on Inflammatory Bowel Disease. Microbial Cell Factories, $12,71$. http://dx.doi.org/10.1186/1475-2859-12-71

[46] Fujimoto, T., Imaeda, H., Takahashi, K., Kasumi, E., Bamba, S., Fujiyama, Y. and Andoh, A. (2013) Decreased Ab- 
undance of Faecalibacterium prausnitzii in the Gut Microbiota of Crohn's Disease. Journal of Gastroenterology and Hepatology, 28, 613-619. http://dx.doi.org/10.1111/jgh.12073

[47] Schwiertz, A., Taras, D., Schäfer, K., Beijer, S., Bos, N.A., Donus, C. and Hardt, P.D. (2010) Microbiota and SCFA in Lean and Overweight Healthy Subjects. Obesity, 18, 190-195. http://dx.doi.org/10.1038/oby.2009.167

[48] Saxelin, M., Tynkkynen, S., Mattila-Sandholm, T. and de Vos, W.M. (2005) Probiotic and Other Functional Microbes: from Markets to Mechanisms. Current Opinion in Biotechnology, 16, 204-211. http://dx.doi.org/10.1016/j.copbio.2005.02.003

[49] Mrazek, J., Tepšič, K., Avguštin, G. and Kopečný, J. (2006) Diet-Dependent Shifts in Ruminal Butyrate-Producing Bacteria. Folia Microbiologica, 51, 294-298. http://dx.doi.org/10.1007/BF02931817 